\title{
Resenha
}

\section{Criando um clima}

\author{
Marcelo Lopes de Souza
}

Weathered: Cultures of Climate, Mike Hulme. Londres, Sage, 2017, 178 pp., ISBN 978-1-4739-2499-4.

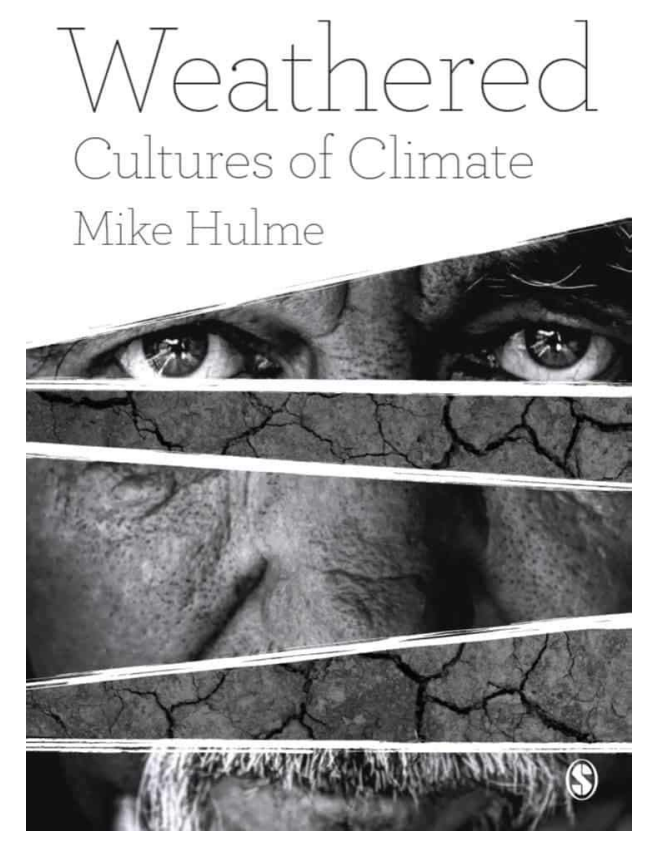

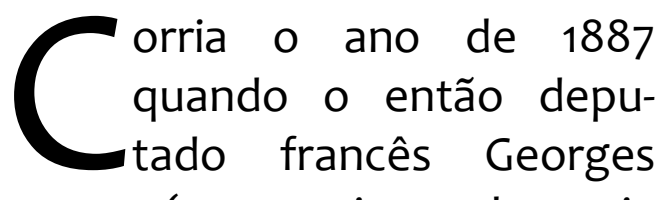

Clemenceau (que mais tarde seria chefe de governo durante muitos anos) disparou a famosa boutade segundo a qual "a guerra é um assunto muito sério para ser confiado aos mili- tares" ("La guerre! C'est une chose trop grave pour la confier à des militaires"). Ao lermos o mais recente livro do geógrafo britânico Mike Hulme, Weathered: Cultures of Climate, ficamos tentados a parafrasear Clemenceau, adaptando a sua tirada para as discussões contemporâ- 
neas sobre "mudança climática": este é um assunto muito sério para ser deixado (apenas) aos climatologistas.

Mike Hulme é, ele próprio, um climatologista, e dos mais proeminentes. Sem ser de modo algum um negacionista climático, Hulme é partidário, não obstante, de uma abordagem que enfatiza a necessidade de compreendermos que a ciência não é neutra, e que mesmo as ciências naturais se inscrevem em contextos culturais e históricos e, por conseguinte, não estão imunes a jogos e relações de poder (assim como os seus praticantes, individualmente considerados, não estão isentos de defeitos tão humanos como vaidade, busca desenfreada por prestígio e ambição desmesurada).

Já em trabalhos anteriores, notadamente no importante livro Why We Disagree About Climate Change: Understanding Controversy, Inaction and Opportunity (HULME, 2009), o autor havia persuasivamente mostrado que, por trás de resultados de pesquisa não raro apresentados como revestidos de suprema autoridade (porquanto "científicos"), há muito mais do que a suposta verdade das ciências. Com efeito, as informações e o conhecimento sobre a "mudança climática" estão mergulhados em um caldo em que se misturam influências midiáticas, interesses políticos, desinformação, dificuldades de comunica- ção (dos próprios cientistas e de outros agentes) e, ainda por cima, o fato de que a "verdade" científica está longe de ser monolítica: há controvérsias e divergências, às vezes em torno de detalhes, e às vezes a propósito de temas mais fundamentais - o que, aliás, é da natureza da própria ciência, e não uma demonstração de fraqueza! Pena que, ao exigirmos dos cientistas infalibilidade e ao Ihes atribuirmos poderes quase sobre-humanos, muitas vezes acabamos por alimentar uma arrogância que é, em última análise, incompatível com o "espírito científico" tolerante, humilde e relativizador preconizado em qualquer manual de Filosofia da Ciência. As páginas que Hulme dedica às previsões científicas, aos "cenários" e às "profecias", tanto em Why We Disagree About Climate Change quanto em Weathered, são muito ilustrativas e, como dizem os anglófonos, thought-provoking. Estas duas frases, extraídas da pág. 117 do décimo capítulo ("Predicting climate") de Weathered, são lapidares, e sintetizam o que pensa o autor:

Humildade e precaução bem podem ser os atributos que as sociedades mais devem cultivar com relação ao futuro climático, para além e acima de pretensões de previsão acurada e conhecimento especial. Para lidar adequadamente ${ }^{1}$ com o clima, as sociedades fariam bem em não esperar ou exigir uma

\footnotetext{
1 "Lidar adequadamente" é a tradução livre de um trocadilho intraduzível, utilizado por Hulme: "weather well".
} 
certeza ainda maior a propósito daquilo que está além do alcance de seus profetas.

Em Why We Disagree About Climate Change, Mike Hulme dedicara suas energias mais sistematicamente a desafiar a entronização acrítica da ciência (sem, no entanto, em momento algum embarcar no niilismo de desvalorizar a ciência moderna, suas realizações e potencialidades). Bem menos longo que a obra de 2009, Weathered é, também, ao mesmo tempo em que mais conciso e mais ensaístico, um livro voltado, segundo o próprio Hulme, para uma tarefa de certo modo anterior ou mais fundamental: auxiliar a perceber e pensar sobre a variedade das experiências culturais e históricas sobre o clima e os fenômenos climáticos, a começar pela compreensão de que a ideia de clima é algo inerentemente cultural. Não à toa, o livro, mesmo sendo da lavra de alguém que, enquanto climatologista, pertence, por sua origem, à tradição dos geógrafos-naturalistas, tem recebido elogios por parte de antropólogos, geógrafos culturais e outros devotados aos "estudos culturais" (cultural studies). Hulme, aliás, tem sido, ele mesmo, um dos nomes mais importantes do fascinante (e para alguns aparentemente improvável) campo da Climatologia Cultural, em que se têm destacado, na América Latina, o geógrafo chileno Hugo Romero e seus colaboradores (ver p.ex. ROMERO ARAVENA et al., 2017 e 2018).
O título original do livro de Mike Hulme é uma palavrinha de difícil tradução para o português, pois são várias as suas acepções. Se, de um ângulo meteorológico ou climatológico, weather significa "tempo", weathered, de sua parte, pode significar diversas coisas, desde "interagir com os 'elementos' (do tempo)" e "estar desgastado por ter sido exposto às intempéries" (isto é, ter sofrido intemperismo) até, figurativamente, a indicação de que se superou um obstáculo ou uma crise (como na construção "I [he/she/we/they] weathered a crisis"). No contexto da obra em questão, o vocábulo weathered faz uma metafórica alusão às intempéries, aos "elementos", para ressaltar a enorme diversidade de situações e resultados. Conforme o autor menciona no quinto capítulo ("Living with climate"), não são apenas entidades inanimadas, como prédios, que interagem com e reagem ao tempo (no sentido de weather); pessoas e lugares também são afetados, à medida que o tempo (no sentido de time) passa: "[s]uas identidades pessoais, práticas sociais, tecnologias materiais e memórias culturais vão sendo modificadas pela atmosfera (...)" (pág. 58). Mas para além disso, podemos acrescentar que a palavra weathered também carrega, no seu âmago, uma brincadeira séria, pois ao significar, entre outras possibilidades, "estar desgastado por ter sido exposto às intempéries", o termo nos remete à essência 
de uma das circunstâncias que Hulme vem problematizando há muitos anos: estamos saturados de informações (amiúde desencontradas) sobre o "aquecimento global" e a "mudança climática global", e nem por isso deixamos de estar confusos. Pelo contrário. Buscamos respostas e soluções absolutas para algo que é, na sua substância, relativo e variável. Se os cientistas e suas instituições, sequiosos por reconhecimento ou insuficientemente atentos às próprias limitações, tantas vezes nos induzem a pensar que modelos matemáticos altamente abstratos podem trazer "o" esclarecimento, no singular, cabe a nós, cidadãos críticos e informados, exigir maior transparência na circulação do conhecimento e debates públicos mais democráticos e polifônicos.

A realidade climática do planeta Terra é a de uma unidade na diversidade. Por um lado, é óbvio que há forças físicas e dinâmicas atmosféricas que depreendem, para sua elucidação, a consideração da escala planetária: das ondas de alcance global que ajudam a organizar o tempo (Ondas de Rossby) às Células de Hadley, passando pelos vórtices estratosféricos e outros tantos fenômenos. Por outro lado, o panorama que Hulme descortina à nossa frente evidencia que também há muita complexidade que ainda se situa além da nossa plena compreensão, e não só isso: acima de tudo, há e tem havido numerosas maneiras de experimentar social e cultu- ralmente os fenômenos físicos objetivos, de modo que as consequências sociais das dinâmicas atmosféricas não podem ser resumidas de forma simplista, como se houvesse a possibilidade de uma interpretação uniforme e absoluta. Em última instância, a experiência humana do(s) clima(s) é sempre uma experiência enraizada em lugares, ou na maneira como, por meio dos lugares e culturas específicos, o tempo é vivenciado e percebido. O conceito de "clima global" pode ser uma abstração útil e cientificamente defensável, mas não deixa de ser uma abstração. Quanto ao sonho de um supermodelo matemático que "explique o clima" em caráter definitivo, ele é uma quimera perigosa, por suas premissas (onipotência da modelagem matemática, as ciências naturais como oráculos supremos) e consequências políticas (desempoderamento crescente do "cidadão comum").

Com uma prosa agradável e cativante, Weathered nos arrosta com a necessidade de refletirmos sobre os diversos aspectos culturais, social-psicológicos, epistemológicos, políticos e econômicos envolvidos nos debates não somente sobre o "clima global" e sua mudança - os quais dominam noticiários, infundem e reproduzem temores e ameaçam justificar toda sorte de medidas governamentais -, mas sobre a experiência humana com o clima ou, antes, com a "ideia de clima". Esta ideia se baseia em uma 
generalização: como todos os geógrafos aprendemos na graduação, 0 clima é a "sucessão habitual dos tipos de tempo". Ocorre que há um intrincado emaranhado de fatores fazendo a mediação entre os fenômenos atmosféricos específicos, na escala espaço-temporal do "tempo", e as macroentidades mais ou menos abstratas que designam os tipos de "clima". A ideia de clima tem se mostrado tão poderosa que, conforme ponderou Mike Hulme, se os climas não existissem, "eles teriam de ter sido inventados - de fato, talvez eles sejam inventados" (pág. 2).

Note-se, porém, que a percepção humana dos climas jamais se restringiu ao entendimento deles enquanto expressões de situações médias. Diversamente, uma das mais marcantes e influentes formas de compreensão do clima no decorrer da história foi, sempre, sublinhar o seu papel como uma espécie de agente, capaz de modelar hábitos, mentalidades, padrões de comportamento e até a inteligência e a moralidade dos povos. "Climas civilizados", "climas nacionais", "climas-problema"... Do geógrafo Ellsworth Huntington, cujo livro Civilisation and Climate, de 1915, é a corporificação acabada do determinismo ambiental, até os preconceitos que atualmente ainda subsistem no senso comum (e até na academia!) pelo mundo afora, Hulme nos faz ver, no delicioso segundo capítulo ("Historicising climate"), o quão rele- vante foi essa maneira de apreensão. Aliás, "foi", não: o autor não deixa escapar que, independentemente de não representar uma linhagem determinista à la Huntington, o IPCC (Painel Intergovernamental sobre Mudanças Climáticas da ONU), por meio de um de seus grupos de trabalho, não deixa de exemplificar a permanência de um entendimento de que os climas, para além de classes e classificações científicas, são forças que geram impactos e, ao se transformarem, transformam as vidas humanas e as sociedades (pág. 17).

Por tudo isso, o estudo científico do(s) clima(s) e suas transformações não deve ser reduzido às suas versões discursivamente dominantes, sob controle das ciências da natureza e, mais especificamente, de disciplinas como a Geofísica e a Meteorologia. Mais do que isso, a opinião pública (e os processos tortuosos de sua formação), a historicidade e as percepções culturalmente variáveis do que sejam o clima e suas mudanças (e as consequências sociais disso) precisam ser levadas muito mais a sério do que tem sido comumente o caso. O clima é criado, e não meramente "dado" em um sentido positivista, e não apenas porque, de maneira objetiva, a civilização urbano-industrial tem afetado as dinâmicas climáticas planetárias, mas também porque o clima e suas particularidades são compreendidos e lidos de modo variável pelos grupos e culturas ao longo da história da humanidade. 
Aceitar isso não quer dizer desdenhar os conhecimentos trazidos pelas ciências da natureza; quer dizer, apenas, que esses conhecimentos precisam ser, o tempo todo, complementados, relativizados e acompanhados com uma dose saudável de ceticismo. É por admitir e sublinhar isso de um jeito que, além de convincente, é inspirador, que Weathered se constitui em um livro indispensável - e de modo algum apenas para os climatologistas. (Não é à toa que um não climatologista se sentiu à vontade para escrever este comentário bibliográfico.)

Os negacionistas climáticos vulgares sugerem que o aquecimento global simplesmente não existe, ou, pelo menos, que ele nada tem a ver com as emissões de $\mathrm{CO}_{2}$ e outros gases de efeito estufa que a humanidade tem despejado abundantemente na atmosfera desde o início da era industrial. Assim procedendo, seja por obscurantismo ou até por motivações escusas, eles nada mais fazem que substituir um veredito alarmante e não raro alarmista por um outro ainda mais simplista, porque absoluto, além de irresponsável. O que Mike Hulme nos leva a perceber é a importância de, justamente, evitar os juízos demasiado fáceis e peremptórios, bons para alimentar manchetes jornalísticas (ou justificar intervenções estatais, ou ainda a inação, no caso dos negacionistas), mas ruins para evidenciar a riqueza do mundo real. De um ponto de vista emancipatório - e, podemos nos atrever talvez a dizer, "iluminista”, no sentido de antidogmático e avesso ao obscurantismo -, isso

\section{Referências}

HULME, Mike. Why We Disagree About Climate Change: Understanding Controversy, Inaction and Opportunity. Cambridge: Cambridge University Press, 2009.

ROMERO ARAVENA, Hugo I.; ESPINOZA, Guillermo; OPAZO, Dustyn; SEPÚLVEDA, Daniela. Cultura, topoclimatología y cambios de clima en la zona andina del desierto de Atacama. Anais do XII Simpósio Brasileiro de Geografia Física Aplicada/I Congresso Nacional de Geografia Física. Campinas: Instituto de Geociências da Unicamp, On-line, 2017. Disponível em <https://ocs.ige.unicamp.br/ojs/sbgfa/article/view/2455>. Acessado em 20/11/2018.

ROMERO ARAVENA, Hugo I. Topoclimatología cultural y ciclos hidrosociales de comunidades andinas chilenas: híbridos geográficos para la ordenación de los 
territórios. Cuadernos de Geografía: Revista Colombiana de Geografía, v. 27, n² 2, pp. 242-261, 2018.

Marcelo Lopes de Souza é Professor Titular do Departamento de Geografia da Universidade Federal do Rio de Janeiro (UFRJ) e pesquisador do CNPq. E-mail: mlopesdesouza@terra.com.br 